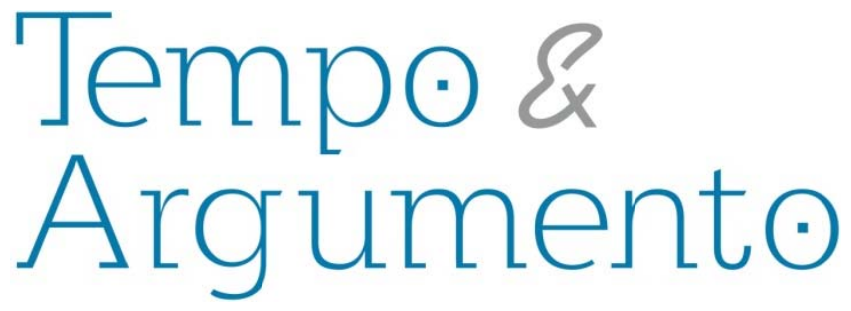

\title{
Ditadura civil-militar, cassações políticas e História em Chapecó
}

\section{Resenha da obra:}

SILVA, Claiton Marcio da. Dos braços do povo à espada dos militares: os anos de chumbo na Fronteira Sul (1964-1970). Florianópolis: Pandion, 2014.

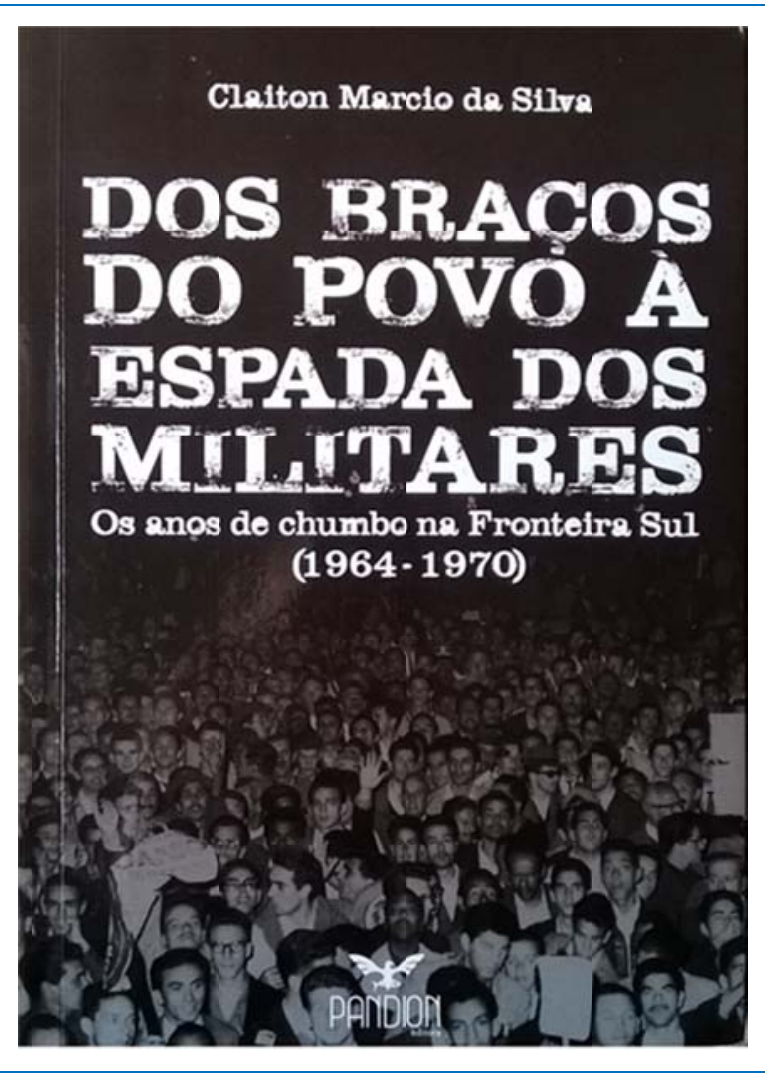

\section{Autor da resenha}

Gustavo Henrique de Siqueira Mestre em História pela Universidade do Estado de Santa Catarina - UDESC. Brasil gustavohst@gmail.com

\section{Para citar esta resenha:}

SIQUEIRA, Gustavo Henrique. Ditadura civil-militar, cassações políticas e História em Chapecó. Revista Tempo e Argumento, Florianópolis, v. 8, n. 17, p. 403 - 408. jan./abr. 2016. Resenha de: SILVA, Claiton Marcio da. Dos braços do povo à espada dos militares: os anos de chumbo na Fronteira Sul (1964-1970). Florianópolis: Pandion, 2014. 
Passados dois anos do cinquentenário do golpe militar de $1^{\circ}$ de abril de 1964 no Brasil, as pesquisas em torno do tema sob variadas perspectivas tomam conta da academia na forma de realização de eventos, publicação de dossiês em revistas e livros. Muito embora o golpe e a ditadura civil-militar que o sucedeu tenham sido debatidos na academia - e fora dela - desde antes do término do período autoritário, foi no distanciamento temporal do acontecimento que se multiplicaram os estudos e se pluralizaram as vertentes explicativas. Se até pouco tempo atrás a ditadura civil-militar era pesquisada enfocando-se quase que exclusivamente os grandes centros urbanos brasileiros, relegando a história do interior nesse período ao segundo plano da historiografia, nos últimos anos ela tem sido levantada por pesquisadores que demonstram a complexidade e a existência de operações repressivas também nas cidades menores do país. Esse é o caso do livro Dos Braços do povo à Espada dos Militares, de autoria de Claiton Marcio da Silva, publicado em 2014 pela editora Pandion.

Claiton Marcio da Silva é natural do oeste do Estado de Santa Catarina e doutor em História pela Casa de Oswaldo Cruz (COC/Fiocruz). Sua área de pesquisa inclui os temas da ditadura civil-militar em Santa Catarina, a formação de jovens rurais nos Clubes 4-S e a cooperação de órgãos internacionais na modernização da agricultura. Atualmente, Silva é professor do Departamento de História da Universidade Federal da Fronteira Sul (UFFS), Campus Chapecó, e vinculado aos Programas de Pós-Graduação em História da UFFS e da Universidade Estadual do Centro-Oeste (UNICENTRO), no Paraná.

O título do livro refere-se a uma fala do ex-prefeito de Chapecó, Sadi de Marco, cassado em 1969: "subi nos braços do povo e desci tangido pela espada dos militares". A obra, segundo o autor, foi pensada com base em dois artigos produzidos em 1997 sobre o período que vai do golpe de 1964 à cassação de Sadi José de Marco, e sobre as eleições para o executivo municipal de 1969, revisitados e reestruturados por Silva para a produção do livro. Os dois artigos se tornaram duas partes da obra, a primeira relativa ao contexto político local que envolve as relações entre os atores e partidos políticos a partir do golpe de Estado, contemplando as cassações de Sadi de Marco (PTB) e Genir Destri (MDB), e a segunda relativa às eleições de 1969 que discute os "ecos das cassações" e o processo conturbado pelo qual passou a realização do pleito. 
Os primeiros capítulos da primeira parte são reservados à análise do anticomunismo e da legitimação dos Atos Institucionais baixados pelo governo autoritário, passando pelo período em que a Aliança Social Trabalhista (PTB e PSD) esteve vigente e elegeu dois prefeitos petebistas em Chapecó, demonstrando que as relações entre a situação e a oposição consistiam em uma disputa pelo poder local e não em uma disputa de dois projetos de sociedade contraditórios. A partir dessa contextualização, o autor aborda a extinção dos partidos políticos com o Ato Institucional n² 2 (Al-2) de 1966 e o processo de formação da Aliança Renovadora Nacional (ARENA) e do Movimento Democrático Brasileiro (MDB) no município, tocando, ainda, a composição da Câmara de Vereadores de Chapecó em 1962 e 1965 e a violência ocorrida no município logo após o golpe, deflagrada na forma de prisões temporárias de petebistas e onde alguns políticos relataram sofrer tortura física e psicológica.

Em seguida são reservados três capítulos para a análise do tema que se destaca no livro de Silva: a gestão e a cassação do prefeito de Chapecó, Sadi José de Marco (PTB). Após expor as principais características da administração do prefeito - embelezamento da cidade, a realização da primeira Exposição Feira Agropecuária e Industrial (EFAPI), as impressões do jornal Folha d'Oeste sobre de Marco e a eleição dele pela Associação Oestina de Imprensa e Radiodifusão como "administrador do ano" por dois anos consecutivos -, o autor parte para a análise dos ataques que o prefeito recebeu da oposição representada por Ivo Patussi (PSD e ARENA) e Rivadávia Scheffer (UDN e ARENA) na gestão do executivo municipal, na qual Silva apresenta a "trama" dessa disputa utilizando como fontes o referido jornal Folha d'Oeste, atas de sessões da Câmara de Vereadores de Chapecó e depoimentos de ex-políticos como Rodolfo Hirsch (ARENA), Rivadávia Scheffer, Ferdinando Damo (PTB e MDB), Odilon Serrano (PTB e ARENA), Félix Trentin (PSD e ARENA) e o próprio Sadi de Marco, realizados na década de 1990 pelo autor e pela socióloga Monica Hass.

Os sucessivos ataques recebidos pelo ex-prefeito, segundo o autor, se explicam pelo crescimento que Sadi de Marco, com 27 anos na ocasião, apresentava no âmbito municipal e pelas projeções políticas que se faziam do petebista para Santa Catarina, quando era tido como provável deputado estadual. As seguidas derrotas do grupo 
udenista e arenista (cabe afirmar que os dois últimos prefeitos eleitos pela Aliança Social Trabalhista, João Destri e Sadi de Marco, eram petebistas) ocasionaram uma ofensiva do partido dos militares contra os trabalhistas em Chapecó, atingindo principalmente Sadi e o também petebista e emedebista Genir Destri (deputado estadual e filho de João Destri) na forma de cassação dos seus mandatos.

Antes de ser cassado por força do Ato Institucional $n^{\circ}$, em abril de 1969, Sadi José de Marco enfrentou duas Comissões Parlamentares de Inquérito ( $\mathrm{CPI}$ ), uma solicitada, que não chegou a ser aberta, e outra que obteve prosseguimento e foi arquivada graças ao voto de vereadores arenistas que se dividiram dentro do partido, um acontecimento pelo qual que Silva evidencia para o leitor as relações complexas que permeavam a política local independentemente das determinações das agremiações partidárias, esclarecendo, assim, que a política chapecoense naquele contexto esteve diretamente influenciada por relações e interesses pessoais, além da constante disputa pelo poder no âmbito partidário presente na antiga dicotomia PSD x UDN e conservada dentro da ARENA (formada majoritariamente, no país todo, por antigos pessedistas e udenistas).

Encerrando a primeira parte do livro, o autor discute a cassação do deputado estadual Genir Destri, também em 1969. Nesse capítulo é apresentada a trajetória de Genir e as relações que cultivou no meio comercial e político através de seu pai, João Destri ${ }^{1}$, além da experiência estudantil e acadêmica, que o influenciaram no início da carreira política. Com um crescimento notável no cenário estadual, Genir Destri foi fundador e presidente do Movimento Democrático Brasileiro de Santa Catarina, popularidade e exposição que também lhe renderam a cassação do mandato. Silva evidencia que as cassações locais tiveram relação mais clara com a ação de opositores que gravavam discursos de petebistas e emedebistas para "denunciá-los" a instâncias do poder federal em Brasília. Além disso, a presença de informantes da ditadura civil-militar no município através do Serviço Nacional de Informações (SNI) teve uma considerável parcela de responsabilidade no caso.

\footnotetext{
${ }^{1}$ Prefeito de Chapecó de 1961 a 1966 pelo PTB e eleito novamente para o cargo em 1969 concorrendo pelo MDB.
} 
Na segunda parte do livro, Silva analisa as eleições de 1969 em Chapecó. Após as cassações no mesmo ano, o clima político local era de que o pleito não aconteceria e seria nomeado um interventor para o cargo. A iniciativa emedebista e a confiança arenista na vitória eleitoral terminaram por confirmar a realização da votação. A ARENA, que até então não havia elegido nenhum prefeito em Chapecó, apostou em João Valvite Paganella e Arcizo Barbieri em suas sublegendas, enquanto o MDB apostou em Nelson Testa e João Destri. Para o autor, os cassados Genir Destri e Sadi de Marco tiveram grande reponsabilidade pela vitória do MDB neste pleito, criando em torno de si uma aura de injustiçados pela ditadura, relembrando das atuações positivas que tiveram e da arbitrariedade pela qual tiveram seus direitos políticos suspensos. A vitória do industrialista/comerciante João Destri em 1969, todavia, não representou um projeto de cidade diferente daquela difundida pelos arenistas locais, consistindo na aposta do desenvolvimento local, no comércio e na infraestrutura que visavam facilitar a instalação e consolidação das agroindústrias nascentes do município. Esse aspecto indica, portanto, que a disputa pela prefeitura nesse contexto girava em torno do poder e não por outra concepção de governo. Nem sequer Sadi de Marco representava uma vertente radical do PTB, sendo cassado por causa de uma carreira promissora na política e não pelos seus atos como prefeito.

Por fim, Silva destaca que a participação da sociedade civil nas denúncias contra os emedebistas moderados, acusando-os de "comunistas", foi fundamental na concretização das cassações e perseguições políticas. Mesmo sem maiores divergências na práxis institucional, as lideranças do MDB representavam um obstáculo para a ARENA, que até 1973 não conseguiria ascender ao executivo municipal, inclusive durante o período do dito "milagre econômico" (1968-1973) e com o conjunto de legislações arbitrárias promulgadas pelo governo federal para facilitar a vitória arenista (como, por exemplo, o voto em sublegenda que pretendia apaziguar as rivalidades entre PSD e UDN dentro da ARENA e canalizar os votos para o partido).

Este livro é publicado em boa hora nacional e local. Apresenta claramente as consequências que o país pode enfrentar em momentos de exceção do ponto de vista legislativo e coercitivo, além de lembrar os episódios violentos pelos quais Chapecó já 
passou (o linchamento de 1950 e o "suicídio" à moda Herzog do vereador petista Marcelino Chiarello em 2011, por exemplo), fazendo-nos contrariar José Murilo de Carvalho e colocando frequentemente o questionamento sobre a permanência de uma prática coronelista na região. A obra de Silva, portanto, não oferece meras curiosidades de figuras conhecidas da política local, oferece conhecimentos indispensáveis a quem procura entender a lógica política local e identificar, na atualidade, suas continuidades.

Recebido em 18/03/2016 Aprovado em 18/04/2016 